\title{
Occurrence of an intrathoracic desmoid tumor following breast cancer treatment: A case report
}

\author{
SERKAN DEĞIRMENCIOĞLU ${ }^{1}$, GOKCEN DEMIRAY $^{1}$, ARZU YAREN $^{1}$, FERDA BIR $^{2}$ and DUYGU HEREK ${ }^{3}$ \\ ${ }^{1}$ Department of Medical Oncology, Fahri Goksin Hematology Oncology Center; Departments of ${ }^{2}$ Pathology \\ and ${ }^{3}$ Radiology, Pamukkale University, Denizli 20070, Turkey
}

Received May 20,2015; Accepted November 27, 2015

DOI: $10.3892 / \mathrm{mco} .2015 .698$

\begin{abstract}
Desmoid tumors are rarely observed tumors that develop from deep muscle and aponeurotic tissues. They are histologically intermediate, and exhibit a local aggressive course. These tumors have been observed in the abdominal region, and are rarely encountered in the thoracic wall. The most effective treatment appears to be surgery. A 59-year-old female patient was admitted with the complaint of right breast pain and a palpable mass. The patient had undergone a modified radical mastectomy surgical procedure of the right breast due to invasive breast carcinoma 10 years before. A mass with a soft tissue density and a size of $44 \times 22 \mathrm{~mm}$ was detected in the thoracic computed tomography of the patient, which subsequently resulted in biopsy followed by surgery. As a result of the pathological examination of the mass, the diagnosis was determined as desmoid tumor. Due to the closeness of the tumor to the surgical margin, the patient was administered radiotherapy and maintenance imatinib treatment was started.
\end{abstract}

\section{Introduction}

Desmoid tumors are rare tumors, which constitute only $0.3 \%$ of solid tumors and $3 \%$ of all soft tissue tumors (1). This tumor, with an incidence of $2-4 /$ million, is also known as aggressive fibromatosis and desmoid-type fibromatosis (2). In addition to an intra-abdominal location, which is the most frequently involved region, it also exhibits thoracic wall involvement at a rate of $10-28 \%$ (3). The current study reports a patient presenting a rare case of desmoid tumor with an extra-abdominal location and a history of mastectomy due to breast cancer.

\section{Case report}

The 59-year-old female patient was admitted due to an increasing pain in the right thoracic region over 2 months and

Correspondence to: Dr Serkan Değirmencioğlu, Department of Medical Oncology, Fahri Goksin Hematology Oncology Center, Pamukkale University, 7 Camlaralti Street, Denizli 20070, Turkey E-mail: sdegirmencioglu@pau.edu.tr

Key words: desmoid tumor, breast cancer, thoracic wall a palpable mass under the ribcage. The patient history revealed that the patient had undergone a modified radical mastectomy of the right breast due to invasive breast carcinoma 10 years prior and adjuvant chemotherapy and radiotherapy were administered following the diagnosis of stage III disease. A thorax computed tomography for the mass was requested from the patient, who used an aromatase inhibitor and was followed up due to breast cancer (Figs. 1 and 2). Upon the detection of a $44 \times 22 \mathrm{~mm}$ mass in the 7th and 8th right intercostal spaces as a result of the tomography, a transthoracic fine needle biopsy was applied. As a result of the biopsy, a mesenchymal tumor was diagnosed. In the cross section of the en-bloc resection, the lesion was poorly circumscribed with infiltration of the soft tissue structures and bone. It was characterized by proliferation of elongated, slender, spindle-shaped cells of uniform appearance. The cells were arranged in long sweeping bundles (Fig. 3A). The tumor cells were immunohistochemically stained with vimentin, smooth muscle actin and cluster of differentiation 117 (CD117) focal positive (Fig. 3B). The mass was conclusively diagnosed as a desmoid tumor. Due to the closeness to the surgical margin, the patient was administered 60 Gy curative radiotherapy and oral maintenance imatinib treatment was started. The patient is currently in the second year of follow-up and maintenance imatinib treatment is continuing. The control images of the patient did not detect any relapse.

\section{Discussion}

A desmoid tumor is a proliferative disease of the fibrous tissue arising from deep muscle and aponeuroses. This tumor is observed twice more frequently in women compared to men and is in the moderate risk group according to the Soft Tissue Neoplasia classification of the World Health Organization (4). The tumor biology exhibits a local aggressive course and it does not cause distant organ metastasis. It is usually observed in the intra-abdominal region and is rarely reported in an intrathoracic location (5). Desmoid fibromatosis may develop on a hereditary basis (familial adenomatosis polyposis syndrome) and such acquired reasons as trauma, history of surgical procedure, laceration and intramuscular injection may also increase risk of incidence (6).

Thoracic desmoid tumors emerge following mastectomy, silicon prosthesis implant to the breast, rib fractures in 


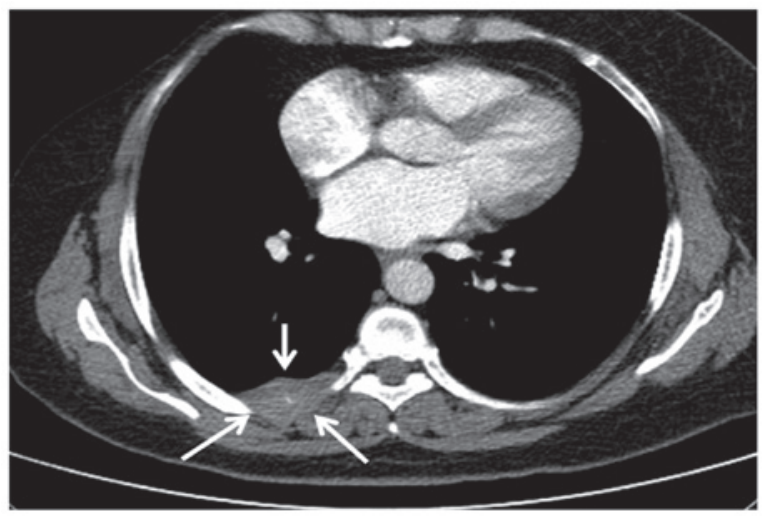

Figure 1. Computed tomography reveals a $44 \times 22 \mathrm{~mm}$ mass in the 7 th and 8 th right intercostal spaces (lung window; arrows).

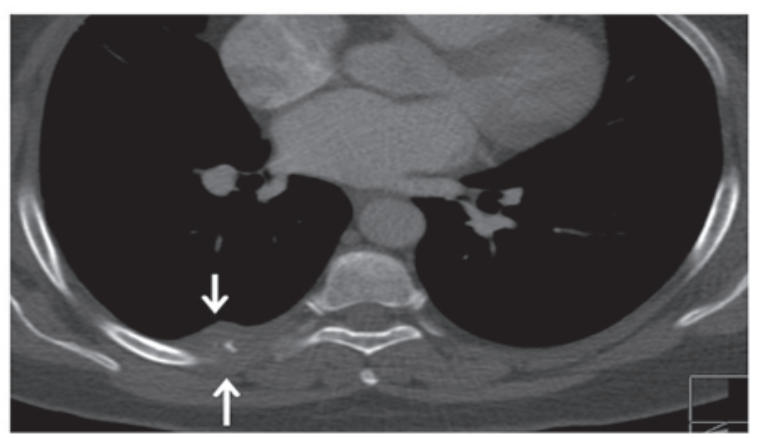

Figure 2. Axial section computed tomography scan. The arrows highlight a soft tissue density (bone window).

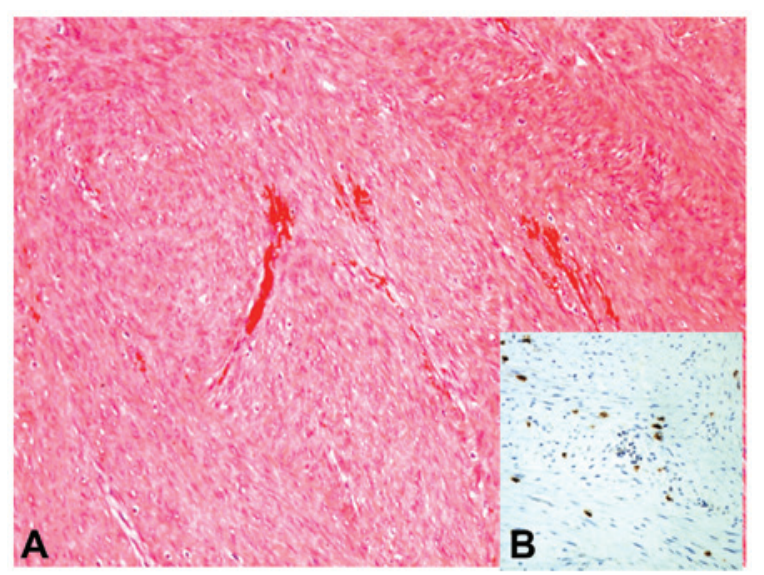

Figure 3 (A) Cellular proliferation of bland spindle cells arranged in long sweeping bundles (haematoxylin and eosin stain; magnification, x10). (B) Occasional tumor cells showed nuclear positivity for cluster of differentiation 117 (immunohistochemistry; magnification, x20).

coronary artery surgery and thoracotomy (7). The present patient is the second case following breast cancer surgery reported in literature, and the silicon implantation following mastectomy in the first case constituted an additional risk factor and therefore differs from the present case (8).

Desmoid tumors arise as palpable masses causing pain, as in the present case. Neurofibromatosis, ganglioneuroma, fibrosarcoma, fibrous tumor and lung cancer must be considered in differential diagnosis (7). By contrast, in the present case, a breast cancer metastasis was primarily considered due to the history of breast cancer and a fine needle aspiration biopsy was applied. Metastasis was eliminated and the mass was diagnosed as a desmoid tumor as a result of the biopsy and subsequently en-block excision of the mass was performed.

The primary treatment for desmoid tumors is surgical resection; however, radiotherapy should also be added to treatment in the event of incomplete surgery, large tumors, relapses and inoperable cases (9). Radiotherapy was added to the treatment in the present case due to close surgical margins. Non-steroid anti-inflammatory agents (10), and hormonal therapy, also including tamoxifen (11), and imatinib (12), have been recommended in the literature. As the sample from the present case was immunohistochemically stained CD117(+), maintenance imatinib treatment was started upon the completion of radiotherapy, which was consistent with a previous study (12).

In conclusion, desmoid tumors should be considered in patients with a history of surgical intervention. They should also be considered in a differential diagnosis when local relapse and metastasis is suspected, particularly following breast cancer surgery.

\section{References}

1. Kabiri EH, AL Aziz S, EL Maslout AE and Benosman A: Desmoid tumors of the chest wall. Eur J Cardio Thorac Surg 19: 580-583, 2001.

2. Okuno SH and Edmons JH: Combination chemoterapy for desmoid tumors. Cancer 97: 1134-1135, 2003.

3. Kostolny M Jr, Prâuer H, Augustin N and Lange R: Extended resection a chest wall desmoid tumour with concominant coronary artey grafting. Eur J Cardiothorac Surg 20: 1040-1041, 2001

4. Fletcher CD: The evolving classification of soft tissue tumours - an update based on the new 2013 WHO classification. Histopathology 64: 2-11, 2014.

5. Papagelopoulos PJ, Mavrogenis AF, Mitsiokapa EA, Papaparaskeva KT, Galanis EC and Soucacos PN: Current trends in the management of extra-abdominal desmoid tumours. World J Surg Oncol 4: 21, 2006.

6. Neuman HB, Brogi E, Ebrahim A, Brennan MF and Van Zee KJ: Desmoid tumors (fibromatoses) of the breast: A 25-year experience. Ann Surg Oncol 15: 274-280, 2008.

7. Allen PJ and Shriver CD: Desmoid tumor of the chest wall. Semin Thorac Cardiovasc Surg 11: 264-269, 1999.

8. Khanfir K, Guinebretiere JM, Vanel D, Barreau-Pouhaer L, Bonvalot $\mathrm{S}$ and Le Cesne A: Unusual problems in breast cancer and a rare lung cancer case. Aggressive fibromatosis of the chest wall arising near a breast prosthesis. J Clin Oncol 21: 2216-2218, 2003.

9. Ballo MT, Zagars GK, Pollack A, Pisters PW and Pollack RA: Desmoid tumor: Prognostic factors and outcome after surgery, radiation therapy, or combined surgery and radiation therapy. J Clin Oncol 17: 158-167, 1999.

10. Nishida Y, Tsukushi S, Shido Y, Wasa J, Ishiguro N and Y Y: Successful treatment with meloxicam, a cyclooxygenase-2 inhibitor, of patients with extra-abdominal desmoidtumors: A pilot study. J ClinOncol 28: e107-e109, 2010.

11. Tsukada K, Church JM, Jagelman DG, Fazio VW, McGannon E, George CR, Schroeder T, Lavery I and Oakley J: Noncytotoxic drug therapy for intra-abdominal desmoid tumor in patients with familial adenomatous polyposis. Dis Colon Rectum 35: 29-33, 1992.

12. Penel N,LeCesne A, Bui BN, Perol D, Brain EG, Ray-Coquard I, Guillemet C, Chevreau C, Cupissol D, Chabaud S, et al: Imatinib for progressive and recurrent aggressive fibromatosis (desmoid tumors): An FNCLCC/ french sarcoma group phase II trial with a long-term follow-up. Ann Oncol 22: 452-457, 2011. 